\title{
eScholarship
}

\section{Glossa Psycholinguistics: Open access by scholars, for scholars}

Fernanda Ferreira, Department of Psychology, University of California, Davis, US, fferreira@ucdavis.edu Brian Dillon, Department of Linguistics, University of Massachusetts, Amherst, US, bwdillon@umass.edu 
We are very pleased to publish our first articles for Glossa Psycholinguistics, a Fair Open Access journal for psycholinguistic research. These articles represent the culmination of nearly two years of behind-the-scenes work that rests upon a substantial outpouring of support for our project from the psycholinguistic community at large. We're proud of the papers that the community has contributed to Glossa Psycholinguistics, and we're happy to use this inaugural editorial to formally mark the publication of these first articles.

There are a number of high-profile and trusted venues in which psycholinguists publish their work. To some, it is perhaps not obvious that another venue is needed. Why Glossa Psycholinguistics, and why now? To our minds, there are two chief reasons. The first is the need for an open access venue for high quality psycholinguistics work that is freely accessible to the entire community in every corner of the world, and for authors and readers alike. The second reason is a desire for a venue for psycholinguistic research that places language science at the core of its mission and publishes work that spans the diverse range of methodologies, frameworks, populations, and theoretical questions that characterize the broad field of psycholinguistics.

As befits an interdisciplinary field like psycholinguistics, existing venues are often themselves interdisciplinary. They generally span a range of different research areas (e.g. acquisition, or second language acquisition) and research traditions (e.g. cognitive neuroscience or theoretical linguistic inquiry). Against this backdrop, our vision for Glossa Psycholinguistics (GP) is to provide a venue in which research on understanding the psychological and neurological basis of language takes central priority, but which explicitly invites work that bridges many of the various research traditions and paradigms that constitute psycholinguistics, broadly construed. Our hope is that the articles published in GP will explore the human capacity for language from a range of perspectives rooted in different traditions of Linguistics, Cognitive Science, Cognitive Psychology, and Neuroscience, but at all times, the focus of the journal will be on making progress on our theoretical understanding of language as a cognitive ability. Readers of GP can expect to learn about language from a range of theoretical perspectives, and contributions to GP will be high quality, impactful publications that contribute meaningfully to our understanding of the human language system. In drawing this focus, our goal is to unite the broad range of researchers working in the language sciences who share this common goal. We envision researchers who might otherwise find their research distributed across multiple different publishing venues able to find common ground and shared interests in the publications in GP, and our hope is that GP will contribute to more porous interactions between different groups of researchers with shared core interests in language.

Another key development over the last decade or two has been the demand for open access to scholarly work. Open access is a key innovation in scholarly publishing that levels the playing field for scholars with diverse backgrounds, by making sure that access to research does not require the purchase of a potentially costly journal subscription. In addition, as the cost of those 
library subscriptions has risen, even wealthy universities have started to balk at paying such a high price to allow their faculty to access what are essentially the products of their own labor. Moreover, because almost all scientific research, and certainly most psycholinguistic investigations, are publicly funded, citizens should not hit a paywall when they try to access scholarly materials. Finally, Open Access is in the interest of authors: research shows that Open Access articles are read and cited more often than articles behind a paywall.

Open access publishing helps to address these concerns, but a number of competing models of open access have emerged. One model allows authors to pay an Article Processing Charge (APC), often many thousands of dollars or euros, to make their work available to anyone with access to a web browser. In many of these cases, the journal still claims exclusive copyright of the material, as in traditional publishing. Another model, and one that we consider to be more equitable, is exemplified by Glossa: a journal of general linguistics (GG), which emerged in 2015 from the Elsevier journal Lingua, with Johan Rooryck serving as its Editor-in-Chief. GG is a Fair Open Access journal, which means that all articles are open access. Moreover, authors pay a much lower APC than is typical in the world of scientific publishing (at the time of this writing, 500USD). In fact, at $G G$ the default is that authors pay nothing to publish: Authors 'opt-in' to pay the APC when they have available institutional or research funds. The GG model has other key features: Authors retain copyright in their publications and are able to use the CC-BY-4.0 license to designate broad sharing and reuse provisions. Additionally, the management model is democratic, with the Editorial Team and Board forming a decision-making collective that also has full ownership of the journal title.

Glossa: a journal of general linguistics had, by 2020, been running successfully for about five years, and it was in January of that year that the possibility of a psycholinguistic offshoot emerged. As a journal of general linguistics, $G G$ had already become an outlet for innovative, theoretically motivated psycholinguistic work, and it seemed that the demand from our community was sufficiently large to justify the creation of a dedicated sister journal with the full agreement of the Editorial Team and Board of GG. Of course, it was important to empirically assess the level of interest from the psycholinguistic community. A one-page document was circulated to email list servers associated with the CUNY Human Sentence Processing Conference and the Architectures and Mechanisms of Language Processing Conference, both of which have hundreds of members. Members of the community were also invited to attend a meeting which was to be held in Amherst, Massachusetts during the 2020 CUNY Sentence Processing Conference. The purpose of this meeting was to discuss the idea of establishing a new psycholinguistics journal and to determine whether the community believed a new journal would fill a need and be viewed as a desirable publishing outlet for psycholinguistic research.

Unfortunately, by March of 2020, the COVID-19 pandemic was in full swing, and so the 2020 CUNY Conference had to go virtual. The meeting to discuss the Glossa Psycholinguistics proposal 
was delayed for a few weeks and eventually conducted online in June. An advantage of this shift to virtual was that it allowed us to expand the list of invitees, with the result that the 90-minute meeting held on 25 June 2020 was attended by more than 100 members of the community from a variety of academic ranks, institutions, countries, and theoretical perspectives. Attendees discussed what they saw as the strengths and weaknesses of the idea, with many following up by email with detailed feedback and suggestions. In response, many important changes to the journal proposal were made: For example, we modified the proposal to emphasize inclusion and scientific ecumenicalism so all members of our psycholinguistics community would feel that the journal was relevant to them and their work.

Of course, one critical aspect of launching a new journal is the financial model. It was essential to develop a plan to ensure the journal would be financially viable and sustainable. A development we hoped would work in our favor was the relatively recent decision by many prominent institutions around the world, including the entire University of California system, to negotiate hard with Elsevier journals, based on a combination of frustration over Elsevier's costs and the desire on the part of many institutions to move towards an open access, nonprofit model of academic publishing. We hoped this attitude would encourage our university libraries to support us not only with verbal encouragement, but with some financial resources as well. In early summer of 2020, we contacted Michael Ladisch, the Scholarly Communications Officer for the University of California Davis Library, to ask whether his office might be able to provide some funds to get this new journal off the ground. Not only did UC Davis Libraries come through with seed funding; they also connected us with eScholarship Publishing, UC's open access publishing program managed by the California Digital Library (thank you to David Barner of UCSD for opening up that channel of communication) to get help with establishing a manuscript management system and publication platform for the journal.

Fortunately, our expenses are lower than for most journals because we are not a for-profit operation. Moreover, no member of the editorial team receives any sort of financial compensation, and eScholarship provides its services free of charge. But we still have costs, including those associated with typesetting, protection of web domain names, brand name protection, and so on. To cover those costs, like $G G$, the funding model for Glossa Psycholinguistics relies on a combination of institutional funding and APCs. However, although open access publishing is now viewed by many in the scholarly community as an essential feature of fair and equitable scientific publishing, some have voiced the concern that APCs may introduce a financial incentive to publish lower quality work. To guard against this, both Glossa journals only request a modest APC from those who have earmarked funds to pay such charges, as mentioned earlier. In addition, to avoid any implicit bias, the matter of the APC is raised only once an article has been officially accepted for publication. Of course, at this stage in the journal's operations we cannot estimate how many authors will be in a position to pay the APC, as the landscape relating to how universities and 
other institutions pay for access to journals and support their scholars in publishing is changing rapidly. This is an issue we will monitor closely over the next several years.

It was important that GP represent a bottom-up, community-led movement, following in $G G$ 's footsteps. Having established interest from the community and some sense that we were on a reasonably solid financial footing, at this point it was time to move on to the critical question of how to select the inaugural Editor-in-Chief. Everyone realized the process had to be open and democratic. We decided to establish a committee of six psycholinguists from a broad range of backgrounds and approaches whose main job was to solicit nominations (including selfnominations) and to make a recommendation. The committee members were Elsi Kaiser, Colin Phillips, Johan Rooryck (chair), Patrick Sturt, Lyn Tieu, and Tessa Warren. We thank them for their invaluable service to the community. The committee sent notices via listservs and social media announcing the search for the inaugural editor and inviting expressions of interest. After considering the candidates and following several rounds of deliberation, the committee decided that the journal should adopt a co-Editor-in-Chief arrangement, and they selected the two of us for that role.

Once we were in place as co-Editors, we began working on the logistics of creating a new journal, and we embarked on the exciting task of appointing Associate Editors and setting up an Editorial Board. After assessing the range of topics we were likely to receive, we reached out to six members of the psycholinguistics community, all of whom enthusiastically agreed to join the team as Associate Editors: Jennifer Culbertson (University of Edinburgh), Roger Levy (MIT), Sharon Peperkamp (Centre National de la Recherche Scientifique), Petra Schumacher (University of Cologne), Florian Schwarz (University of Pennsylvania), and Ming Xiang (University of Chicago). Due to a variety of commitments, Roger will be stepping down a bit earlier than the other Associate Editors, and when he does his area will be taken over by Tal Linzen (New York University). The Editorial Board is composed of nearly 50 early-career and more senior scientists who cover the full range of scientific topics and who represent the international psycholinguistics community.

The editorial team functions as a collective, with decisions made via discussion and consensus. We agreed that the journal should publish theoretical reviews as well as empirical articles, including registered reports. We affirmed our commitment to a range of open science practices: for example, authors are required to make available their data and analysis scripts to reviewers at the time of submission and to all readers once an article is published (exceptions are considered on a case-by-case basis). We use double-masked peer review to ensure reviewers are not biased by knowing authors' identities and reviewers feel free to provide frank and honest feedback. At the same time, the editors require that reviewers provide constructive feedback to authors, and rude or abusive language is not tolerated. If offensive language is included in a review, we ask reviewers to remove it. 
Getting to this point has truly been a community effort. We'd like to close this editorial by thanking the many people who have helped Glossa Psycholinguistics get to where it is. We gratefully acknowledge the eScholarship team-with special gratitude to Justin Gonder, Rachel Lee, Catherine Mitchell, and Lisa Schiff-for making their services available to us free of charge and for investing enormous amounts of time into helping us establish the journal. Without them this project would certainly not have succeeded. We'd like to thank the dozens of community members who turned out to help shape this project in the initial meetings, the dozens of researchers who committed themselves to serving on the founding GP editorial board, and the dozens of scholars who have sent high quality manuscripts to GP, even before it had published a single article. We also want to acknowledge the library systems at the University of Edinburgh (thank you Jennifer Culbertson), MIT (thank you Roger Levy), the Centre National de la Recherche Scientifique (thank you Sharon Peperkamp), the University of Cologne (thank you Petra Schumacher), and the University of Pennsylvania (thank you Florian Schwarz) for additional financial support.

Because of this financial support we're optimistic we can put out a high quality journal while keeping APCs not just opt-in, but affordable for those who can pay. The goal is that everyone in principle can publish in GP, and those who can pay do so-which subsidizes the costs for everyone. The journal is thus truly community oriented. But we wish to go further: We want the journal to reflect the needs and views of the community. We therefore welcome your feedback on any aspect of the journal and we will do our best to respond appropriately to your suggestions and concerns. Our hope is that within a few years we will be seen as the premier journal for psycholinguistic research, and at least the more senior of the two co-Editors hopes to see the journal firmly in the hands of the current generation of psycholinguists who are revolutionizing the field with their impressive commitment to interdisciplinarity, empirical rigor, and fairness. We look forward to receiving your best work! 


\section{Competing Interests}

The authors have no competing interests to declare. 